\title{
Cholera with severe renal failure in an Italian tourist returning from Cuba, July 2013
}

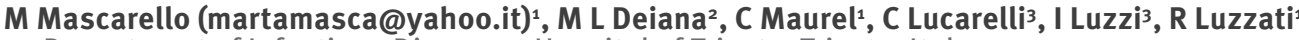

1. Department of Infectious Diseases, Hospital of Trieste, Trieste, Italy

2. Department of Microbiology, Hospital of Trieste, Trieste, Italy

3. Department of Infectious, Parasitic and Immune-mediated Diseases, Istituto Superiore di Sanità, Rome, Italy

Citation style for this article:

Mascarello M, Deiana ML, Maurel C, Lucarelli C, Luzzi I, Luzzati R. Cholera with severe renal failure in an Italian tourist returning from Cuba, July 2013 . Euro Surveill. 2013;18(35): pii=20572. Available online: http://www.eurosurveillance.org/ViewArticle.aspx?Articleld=20572

Article submitted on 21 August 2013 / published on 29 August 2013

In July 2013, an Italian tourist returning from Cuba was hospitalised in Trieste, Italy, for cholera caused by Vibrio cholerae $0_{1}$ serotype Ogawa with severe renal failure. An outbreak of cholera was reported in Cuba in January 2013. Physicians should consider the diagnosis of cholera in travellers returning from Cuba presenting with acute watery diarrhoea.

\section{Case report}

An Italian man in his late 40 s with cholera was hospitalised in Trieste, Italy, in July 2013. He had returned from Cuba, where he had spent two weeks in Havana. He did not seek medical advice before travelling. While in Cuba, he drank tap water and ate fruits and vegetables washed with tap water. He reported no direct contact with sick individuals there. On the last day of his stay, he ate raw seafood including sea urchin and crabs, which he caught himself, along the coast of Havana. The following day, during the flight to Italy, he developed watery diarrhoea, severe weakness, tachycardia, muscle cramps, dizziness, abdominal pain, nausea and vomiting.

The day after his return, he was admitted to hospital with watery diarrhoea, dehydration, loss of $10 \mathrm{~kg}$ of body weight, hypotension and severe oligoanuric renal failure. On admission, laboratory analysis of peripheral blood showed leukocytosis (white blood cell count of $16,810 / \mu \mathrm{L}$; norm: $4,000-11,000 / \mu \mathrm{L})$, high serum creatinine level $(5.69 \mathrm{mg} / \mathrm{dL}$; norm: $0.50-1.30$ $\mathrm{mg} / \mathrm{dL}$ ), metabolic acidosis ( $\mathrm{pH}$ : 7.16; norm: 7.35-7.45), low bicarbonate $(11.3 \mathrm{mmol} / \mathrm{L}$ (norm: 22-26 mmol/L), hypokalaemia (2.7 mEq/L; norm: 3.50-5.00 mEq/L).

He underwent continuous intravenous hydration and correction of metabolic acidosis and hypokalaemia. He also had a haemodialysis session and started empirical antibiotic therapy with ciprofloxacin (200 mg twice daily for 7 days).

The patient's condition progressively improved, the laboratory test abnormalities returned to normal values and he was discharged 10 days after admission.
The patient's travel companion had consumed the same meals during their stay in Cuba, except for the raw seafood. The companion did not develop any symptoms.

Vibrio cholerae was isolated from the patient's stool samples taken on the first day of hospitalisation. The serogroup and serotype were confirmed by slide agglutination in polyvalent $\mathrm{O}_{1}$ and mono-specific Inaba and Ogawa antisera (Oxoid Ltd, United Kingdom) as $V$. cholerae $\mathrm{O}_{1}$ serotype Ogawa. Double mismatch amplification mutation assay (DMAMA) polymerase chain reaction (PCR) was performed in order to discriminate between the classical, El Tor, and Haitian type of ctxB allele (encoding cholera toxin B subunit) [1].

Antimicrobial drug susceptibility testing of the isolated $V$. cholerae strain was performed by the disk diffusion method, according to the Clinical and Laboratory Standards Institute (CLSI) [2], and by Etest (Oxoid Ltd, United Kingdom), for phenotypic characterisation of the isolate.

The strain was positive for the Haitian type of $\operatorname{ct} x B$ allele: it displayed resistance to sulfonamide, streptomycin, trimethoprim/sulfamethoxazole, nalidixic acid and ceftazidime, and susceptibility to cefotaxime, tetracycline, ampicillin, chloramphenicol and gentamicin. The strain showed also reduced susceptibility to ciprofloxacin (minimum inhibitory concentration: $0.25-0.5$ $\mathrm{mg} / \mathrm{L})$.

Genotyping was performed by pulsed-field gel electrophoresis (PFGE) analysis using the restriction enzymes Notl and Sfil according to the PulseNet United States protocol [3]. The PFGE patterns were defined as KZGS12.0097(Sfil) and KZGN11.0124 (Notl), corresponding to those currently observed in most $V$. cholerae strains from Haiti [4].

\section{Background}

Cholera is an acute, secretory diarrhoea caused by infection with $V$. cholerae of the $0_{1}$ or $0_{139}$ serogroup. 
The infection is caused by ingestion of food or water contaminated with the bacterium. The clinical presentation of infection may range from mild to massive watery diarrhoea, shortly progressing to severe volume and electrolyte depletion, severe hypotension and renal failure, with death occurring within hours [5].

In 2012, the World Health Organization (WHO) recorded 245,393 cholera cases and 3,034 deaths globally, with a case fatality rate of $1.2 \%$, representing a $58 \%$ decrease in number of cases compared with the previous year [6]. However, the actual number of cases is known to be much higher than those reported [6]. In 2012, Cuba reported a cholera outbreak following a major outbreak in Haiti and the Dominican Republic that began at the end of 2010. A total of 500 cases were recorded in Cuba by the end of 2012 [7]. This was the first cholera outbreak in Cuba since the mid19th century [7]. Another outbreak of cholera occurred in Havana in January 2013: on 14 January, 51 cases of infection with $V$. cholerae serogroup 01 , serotype Ogawa, biotype El Tor were confirmed in Havana [8].

Cuba is an important tourist destination. It is estimated that in 2010, more than 2.5 million tourists visited Cuba, of whom around 32\% were European residents, mostly from Italy, Spain and Germany [9].

Cases of imported cholera in Italy are very rare: the last confirmed case was in 2006 [10]. After the Hispaniola cholera epidemic started in Haiti in 2010, no cases of imported cholera have been reported in Italy.

\section{Discussion}

Cholera can be a life-threatening disease. Early recognition, based on travel history and clinical features, is the cornerstone of successful patient management. Renal dysfunction can be present in the course of the disease, as occurred in our patient. Oligoanuric acute kidney injury, tubulointerstitial nephritis and persistent metabolic acidosis can be potential complications of the infection itself or secondary to volume depletion [11]. Taken together, the phenotypic and genetic characterisation of $V$. cholerae $0_{1}$ isolated from our patient shows its relationship with Haitian epidemic strains.

On 9 August 2013, another four cases of cholera in persons returning from travel to Cuba were reported to WHO, two from Venezuela and two from Chile [12]. On 23 August, the Pan American Health Organization (PAHO) reported seven cases of cholera in persons who had travelled to Cuba from Europe: two from Germany, three from Italy (one of whom was our patient, who had been reported in the PAHO update of 14 August [12]), one from Netherlands and two from Spain [13].

In January 2013, the risk of cholera in travellers visiting Cuba was considered to be low [14]. However, the risk has increased, given the outbreak in January 2013, the recent imported cholera cases and the high number of tourists visiting Cuba. Travellers to Cuba should seek advice from travel medicine clinics in order to assess their personal risk and to be aware of preventive hygiene measures [15]. On 23 August, Cuba reported that there have been 163 cases of cholera in 2013 in the province of Havana, Santiago de Cuba and Camaguëy, as well as in other municipalities. Public health awareness campaigns were intensified during the summer [13].

Physicians should consider the diagnosis of cholera in patients returning from Cuba who present with acute watery diarrhoea.

\section{Acknowledgements}

We are grateful to Dr Alessandro Camporese, Microbiology, Hospital of Pordenone, Italy, who provided the preliminary microbiological investigation and to Dr. Giuliano Boscutti, Department of Nephrology and dialysis, Hospital of Trieste, Italy, for the clinical care of the patient in the initial phase of hospitalisation. We are grateful to PulseNet US-CDC for the PFGE pattern definition.

Conflict of interest

None declared.

Authors' contributions

Marta Mascarello wrote the manuscript, Maria Luisa Deiana performed the microbiological tests, Ida Luzzi confirmed the serogroup and serotype and provided the antimicrobial drug susceptibility testing, Claudia Lucarelli performed the molecular characterisation ( DMAMA-PCR and PFGE) of the isolate, Cristina Maurel read and revised the manuscript, Roberto Luzzati wrote and revised the manuscript. 


\section{References}

1. Naha A, Pazhani GP, Ganguly M, Ghosh S, Ramamurthy T, Nandy RK, et al. Development and evaluation of a PCR assay for tracking the emergence and dissemination of Haitian variant ctxB in Vibrio cholerae 01 strains isolated from Kolkata, India.

J Clin Microbiol. 2012;50(5):1733-36. http://dx.doi.org/10.1128/ JCM.00387-12. PMid:22357499. PMCid:PMC3347119.

2. Clinical and Laboratory Standards Institute (CLSI). Performance standards for antimicrobial susceptibility testing; twentieth informational supplement. Wayne, PA: CLSI; 2010. CLSI document M100-S20.

3. PulseNet United States. Standard operating procedure for PulseNet PFGE of Vibrio cholera and Vibrio parahaemolyticus. PulseNet United States; last updated April 2013. PNLo6. Available from: http://www.cdc.gov/pulsenet/PDF/vibrio_ pfge_protocol-508c.pdf

4. Katz LS, Petkau A, Beaulaurier J, Tyler S, Antonova ES, Turnsek MA, et al. Evolutionary dynamics of Vibrio cholerae $\mathrm{O}_{1}$ following a single-source introduction to Haiti. MBio. 2013;4(4):e00398-13. http://dx.doi.org/10.1128/mBio.0039813. PMid:23820394. PMCid:PMC3705451.

5. Harris JB, LaRocque RC, Qadri F, Ryan ET, Calderwood SB. Cholera. Lancet. 2012;379(9835):2466-76. http://dx.doi. org/10.1016/S0140-6736(12)60436-X

6. Cholera, 2012. Wkly Epidemiol Rec. 2013;88(31):321-34 PMid:23980290.

7. Pan American Health Organization (PAHO). Epidemiological update. Cholera. 7 January 2013. Washington, DC; PAHO; 2013. Available from: http://www.paho.org/ $\mathrm{hq} /$ index.php?option $=\mathrm{com} \_$docman\&task $=\mathrm{doc}$ view\&gid $=19656 \&$ Itemid $=$

8. Pan American Health Organization (PAHO). Epidemiological update. Cholera. 15 January 2013. Washington, DC; PAHO; 2013. Available from: http://www.paho.org/ $\mathrm{hq} /$ index.php?option $=$ com_docman\&task $=\mathrm{doc}_{-}$ view\&gid $=19785$ \&ltemid $=$

9. Caribbean Tourism Organization (СТO). Cuba [country statistics and analyses]. CTO; 2010. p. 41-4. Available from: http://www. onecaribbean.org/content/files/Strep2BVItoDominica2010.pdf

10. Cholera, 2006. Wkly Epidemiol Rec. 2007;82 (31) 273-84. PMid:17679181.

11. Reyes-Corcho A, Pinsker RW, Sarkar S, Bagheri F, Patel MC, Lam P, et al. Cholera gravis associated with acute renal failure in a traveler from Haiti to the United States. Travel Med Infect Dis. 2012;10(5-6):236-9. http://dx.doi.org/10.1016/j. tmaid.2012.10.002. PMid:23137437.

12. Pan American Health Organization (PAHO). Epidemiological update. Cholera. 14 August 2013. Washington, DC; PAHO; 2013. Available from: http://www.paho.org/ $\mathrm{hq} /$ index.php?option $=$ com_docman\&task $=$ doc view\&gid $=22575 \&$ Itemid $=$

13. Pan American Health Organization (PAHO). Epidemiological update. Cholera. 23 August 2013. Washington, DC; PAHO; 2013. Available from: http://www.paho.org/ $\mathrm{hq} /$ index.php?option $=\mathrm{com} \_$docman\&task $=\mathrm{doc}$ view\&gid $=22751$ \&ltemid $=$

14. European Centre for Disease Prevention and Control (ECDC) Update: outbreak of cholera in Cuba, potential risk for European travellers. 17 January 2013. Rapid risk assessment. Stockholm: ECDC; 2013. Available from: http://ecdc.europa.eu/ en/publications/Publications/cholera-cuba-risk-assessment17-jan-2012.pdf

15. Brunkard JM, Newton AE, Mintz E. Infectious diseases related to travel. Cholera. In: Centers for Disease Control and Prevention, Brunette GW. CDC health information for international travel 2014. [CDC health information for international travel is commonly known as the Yellow book]. Oxford University Press USA; 2013. Available from: http://wwwnc.cdc.gov/travel/yellowbook/2014/ chapter-3-infectious-diseases-related-to-travel/cholera 